\title{
ASSEMBLING WALL PANELS WITH ROBOTIC TECHNOLOGIES
}

\author{
Frans van Gassel \\ Construction Management and Engineering \\ Technische Universiteit Eindhoven \\ PO Box 513, 5600 MB Eindhoven \\ f.j.m.v.gassel@bwk.tue.nl
}

\author{
Pascal Schrijver \\ Jos Lichtenberg \\ Building Technology \\ Technische Universiteit Eindhoven
}

Robots are only incidentally used to assemble wall panels in high-rise buildings, even though robotic technologies for various applications are available. These applications can improve construction site safety and increase the productivity of the assembly process. A research project initiated at Eindhoven University of Technology (TU/e) in the Netherlands aims to develop an integral design for a curtain wall. The curtain wall's assembly, disassembly and user functions are integrated into a single concept. The focus lies on the assembly/disassembly process and the use of new robotic technologies.

This paper presents the initial results of a survey of currently available strategies for the assembly of curtain wall systems, a description of the functions and the design requirements.

The purpose of this research is to explore the limits of currently available robotic technologies in designing a curtain wall for the entire life cycle.

Keywords: curtain wall, wall panels, robot technologies, construction site safety

\section{INTRODUCTION}

As a rule, the conditions under which the wall panels of high-rise buildings are assembled and disassembled are neither safe nor labour-friendly. Moreover, climatic conditions make production times uncertain.

In addition, the trend is for curtain walls to be replaced at an early stage as the technical and visual performance no longer satisfy the applicable requirements. After a certain period, the curtain wall is disassembled and a new one installed.

Curtain walls from the 1950s and 1960s do not meet current structural requirements. In addition, they are suffering a bit of an image problem (Bouwen met Staal, 1996).

Wall panel assembly is performed at great heights. In 2004, $18.5 \%$ of accidents in the Netherlands involved falls from heights (Cobouw, 2005). Although various measures have to be taken to prevent falls from high-rise constructions, these generally hamper assembly process efficiency. See Figure 1.

For instance, guard rails have to be installed or the installers have to use safety lines. These measures, however, do not benefit productivity.

Despite the fact that several robots have already been designed that address these problems, Arai (2005) feels that 'the working abilities of previously developed robots were not sufficient for them to be put into practical use in building construction'.

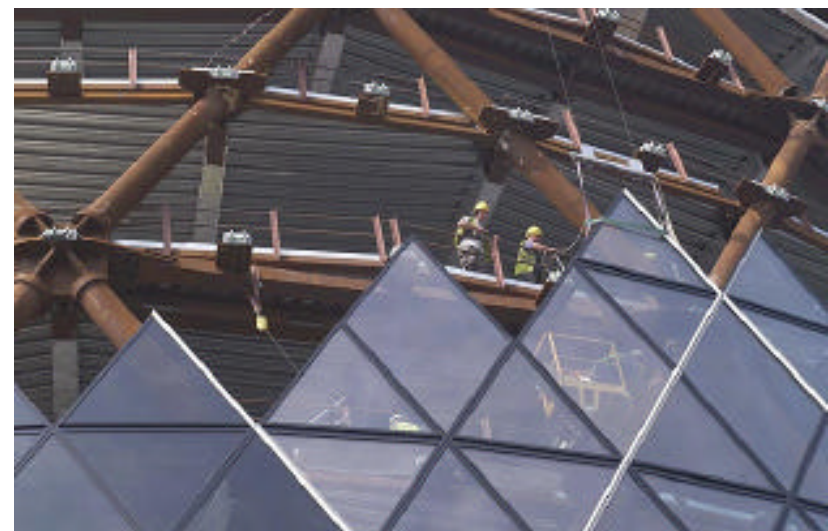

Figure 1: Curtain wall assembly can be extremely dangerous. The photo shows the assembly of the wall panels for the St. Mary Axe high-rise building in London. (Photo: Grant Smith)

New robot technologies and materials can help us to solve the problems identified above. The strategic Research Agenda for the European Construction Sector (ECTP, 2005) believes that 'automation and robotics also offer important opportunities to improve construction processes'. The objective is to develop 'intelligent equipment and materials for construction, based on mechanisation, automation or robotisation. Recent trends in miniaturisation and the mass production of robots open the way to a much broader implementation of these concepts in the construction workplace'. Examples include mini-actuators (or even micro-actuators) and microsensors that can see to, for instance, the precise positioning or user functions of the wall panels. See Figure 2. These technologies are already used in robot systems. See Figure 3. 


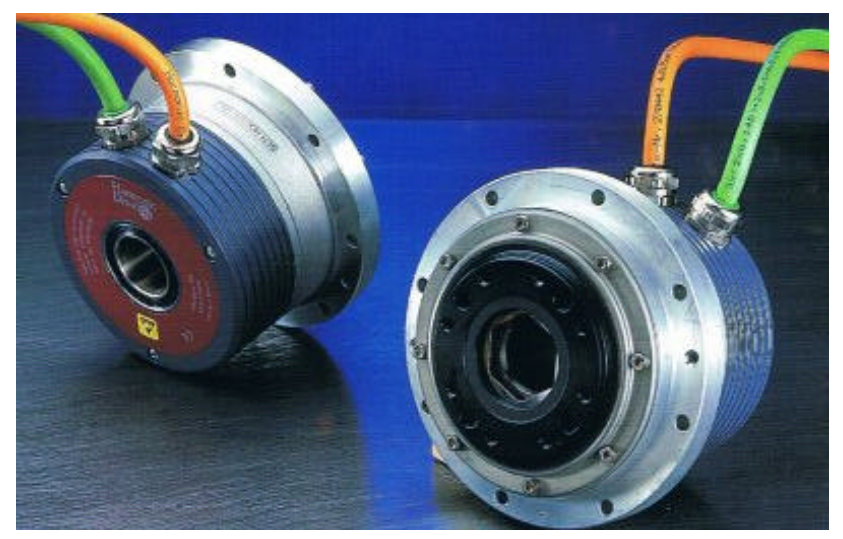

Figure 2: Mini-actuator. A device that combines an AC motor, gearbox and encoder in a package weighing $400 \mathrm{~g}$ and occupying a volume of just $50 \mathrm{~mm}^{3}$. (Harmonic Drive)

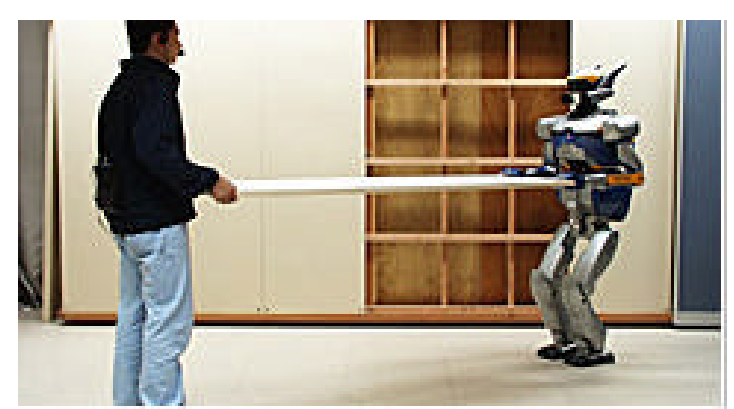

Figure 3: KAWADA Japan developed a humanoid robot for panel assembly. This robot is an example of what is possible with the new technologies, including compactness, interactivity, manoeuvrability and limited weight.

The integral design of the assembly process, the curtain wall and the wall panels is necessary to apply new robotic technologies.

Building clients and users asked for safety construction processes and valuable buildings during the life cycle.

The goal of the research study described in this paper is to 'develop the design requirements for a curtain wall that is self-supporting during its entire life cycle and integrates the wall's assembly, user and disassembly functions as much as possible into a single design'.

\section{EXISTING ASSEMBLY TECHNOLOGIES}

In recent years, a number of automatic systems has been developed and used on construction sites. Figures 4 up to and including 9 present several examples.

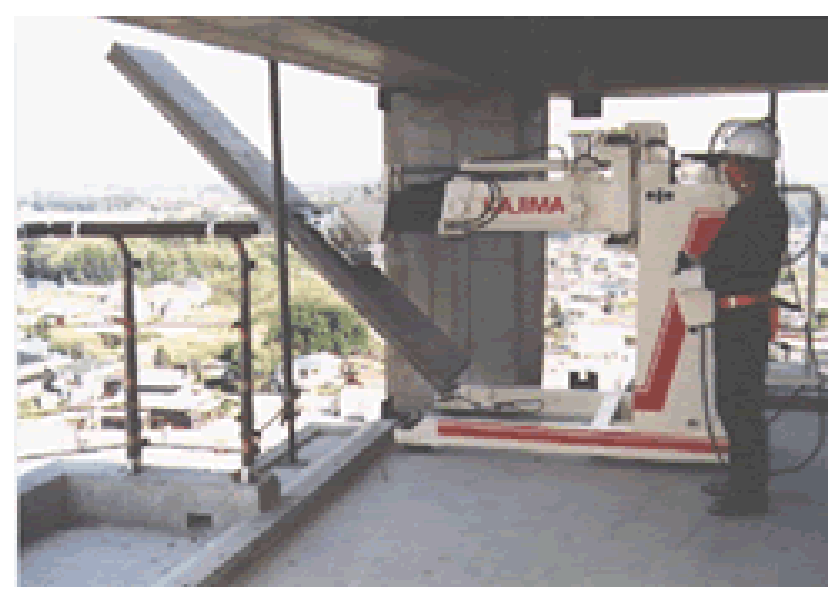

Figure 4: The 'Mighty Hand' (KAJIMA Japan) lifts heavy panels used in construction, including concrete or glass curtain walls. The robot operates under human supervision. (IFR 2006)

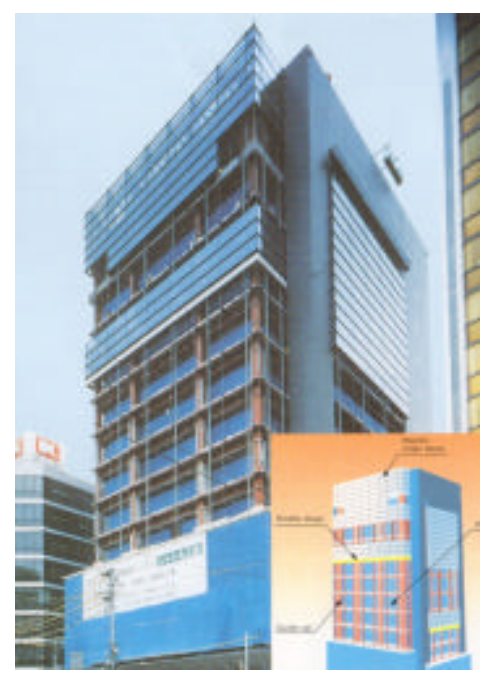

Figure 5: The FUJITA Shuttle method. 'This building system facilitates the construction of extra large exterior wall panels assembled on the ground. Panels covering the entire perimeter of the building are hoisted into place one panel at a time and positioned automatically, working from the top down.' (Iwanmoto et al 1994)

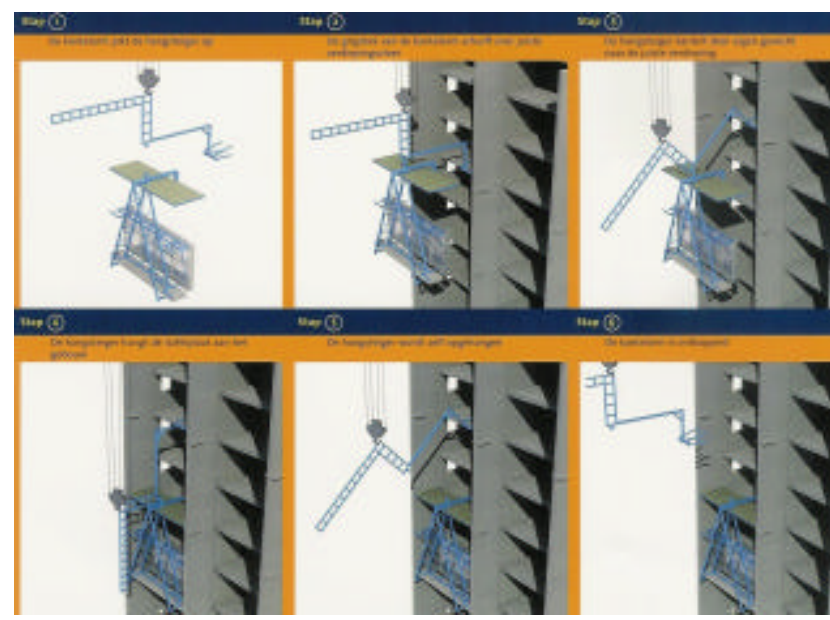

Figure 6: A mechanised panel assembly system developed by BALLAST NEDAM. 'The panels are installed using a flying scaffold suspended from a tilting arm. The tower crane uses this tilting arm to pick up the flying scaffold. The tilting arm's grab is positioned above the floor where installation will take place. Using its own weight, the flying 
scaffold is tilted into place on the proper floor. The flying scaffold then attaches the facade element to the building and is then suspended itself. This is done using a hydraulic system. Once disconnected, the tilting arm can be used for the next flying scaffold. (VOBN 2003)

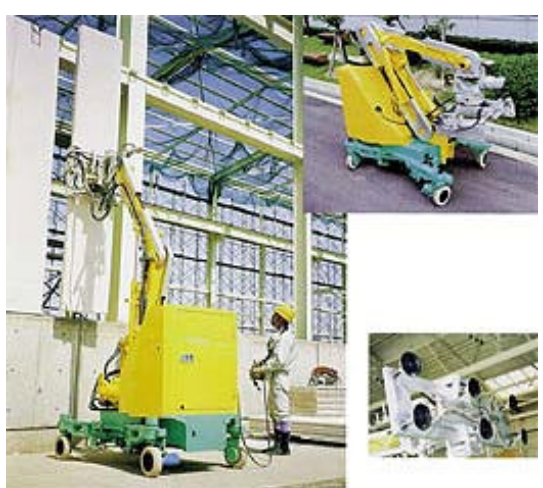

Figure 7: This multi-jointed handling robot assists in the installation of heavy exterior and interior materials (FUJTA Japan).
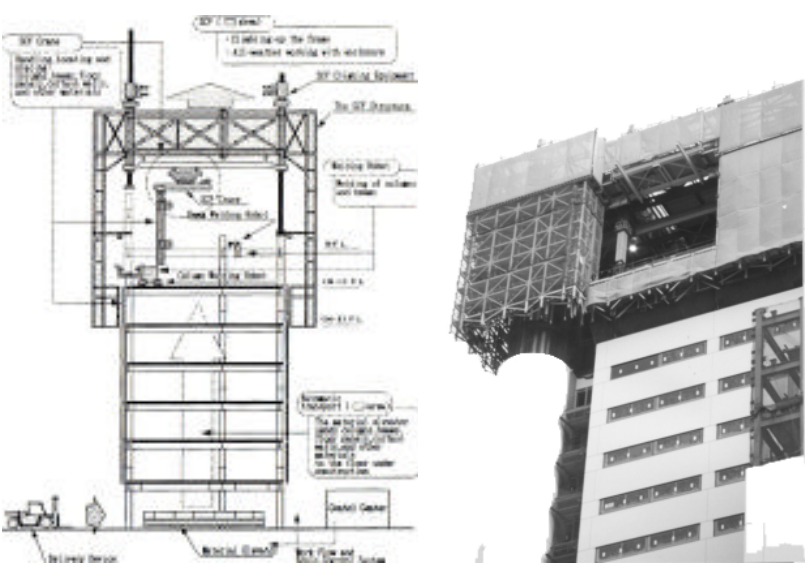

Figure 8: The facade assembly component of the OBAYASHI Automated Building Construction System (ABCS). The same concept can also be seen in the Canopy, SMART and other automated construction systems.

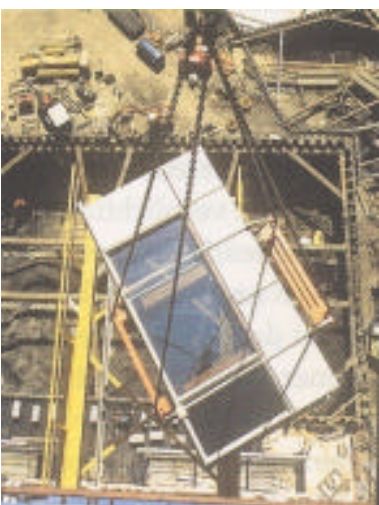

1. Wall panels are transported to the floor where they are required.

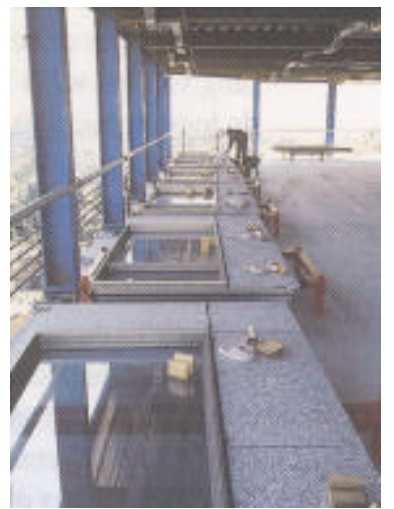

2. Wall panel depot on the floor where the panels will be installed.

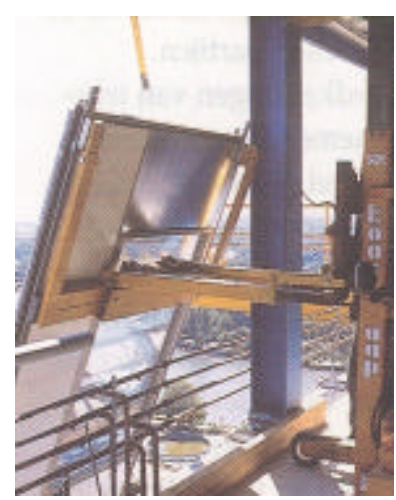

3. Wall panels are moved outside.

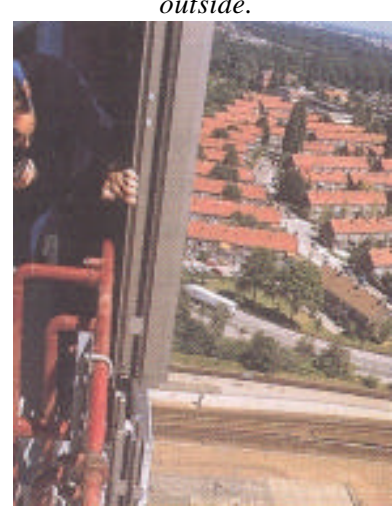

5. Wall panels are assembled.

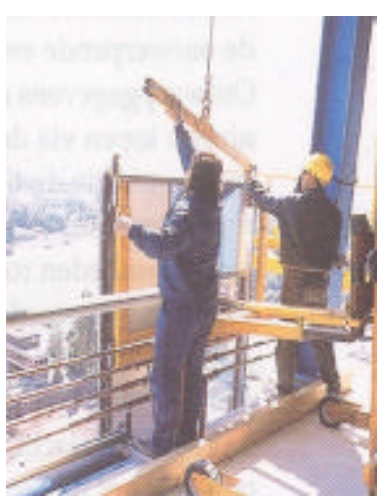

4. Wall panels are connected to the tower crane.

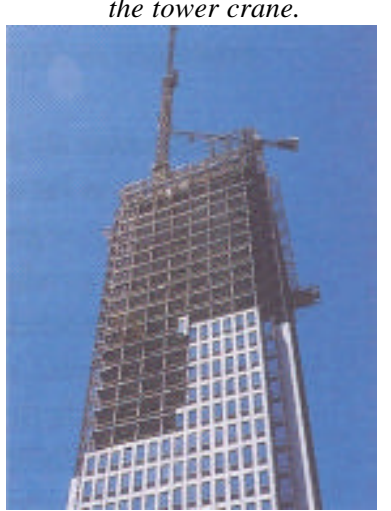

6. Exterior view.
Figure 9: Wall panel assembly steps. Rembrandt Tower in Amsterdam.

Other currently developed systems include:

- SAMSUNG's curtain wall installation robot: built and tested at an actual construction site. (Yu et al, 2005)

- EZ-ten: a PC curtain wall suspending device developed by SHIMIZU.

- TO-AUTO FX: a robot for cladding works developed by TODA.

- FUJITA developed a turn-control hanging device and an automatic horizontal control/remote hitch remover for panels. This device is designed to perform the horizontal control of the attitude of the hanging load in a direction of horizontal turn, in ways which consider the conditions under which the load must be transported and the effect of the wind. In automatic operation the built-in optical fibre gyro allows for maintaining the horizontal direction of hanging load in a given direction. The systems described above offer a brief overview of possible techniques which can be used in the development of an integral curtain wall system.

\section{METHOD}

We drew up the following questions in order to gain information that would help us achieve the formulated goal:

1. How are the wall panels of curtain walls currently assembled?

2. Where are the problems encountered in the process? 
3. Where can robot technologies be used to solve problems?

4. How can the different functions of a curtain wall be integrated?

To find the answers to these questions, we completed a literature review and used the Systematic Analysis and Design Techniques (SADT) to describe the transportation and assembly processes.

\section{RESULTS}

3.1. Wall panel assembly

Figure 8 outlines the assembly process of wall panels supplied from the building depots.

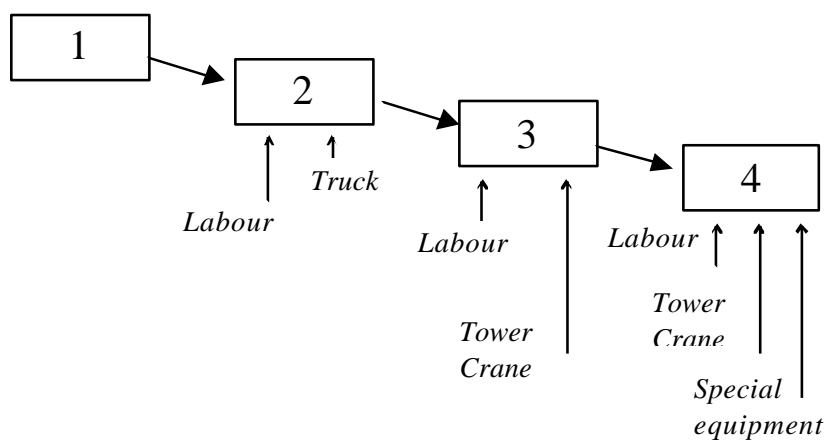

Figure 8: The four assembly sub-processes when supplying wall panels from the on-site depots:

1. Wall panels are manufactured at the factory.

2. Wall panels are transported to the construction site by truck.

3. On the construction site, wall panels are transported to the depot by tower crane.

4. Wall panels are assembled using the tower crane and special equipment from the depots.

Figure 9 presents the assembly process of wall panels supplied from a truck.

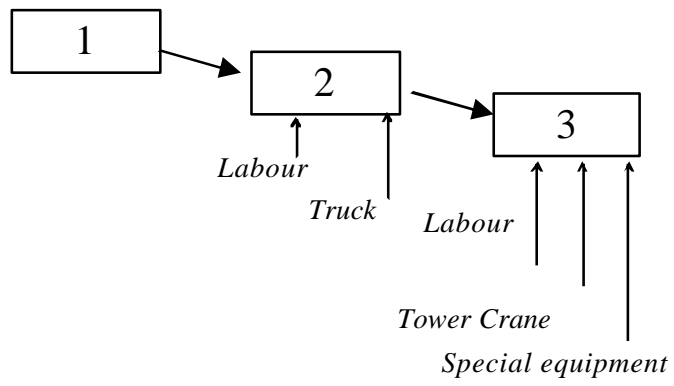

Figure 9: The three assembly sub-processes when supplying wall panels from a truck:

1. Wall panels are manufactured at the factory.

2. Wall panels are transported to the construction site by truck.

3. Wall panels are assembled using the tower crane and special equipment from the truck.
3.2. Problems during the assembly process

The analysis revealed that problems requiring improvement occur during the fourth sub-process (Figure 8) and the third sub-process (Figure 9). It is necessary to know from which depots the construction elements will be supplied. The case studies show that there are four starting locations in the wall panel assembly process. See Figure 10.

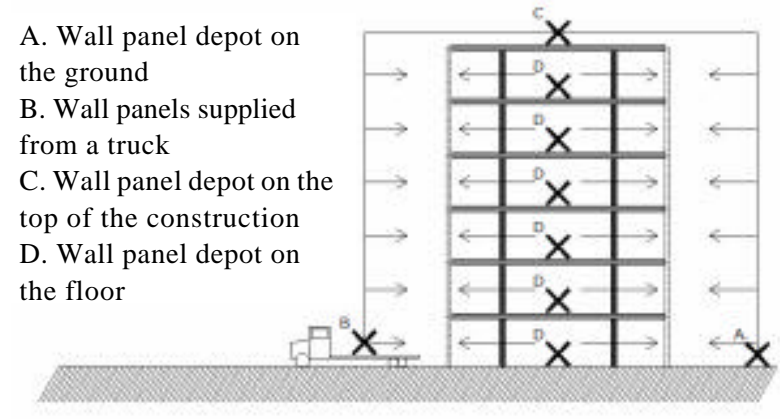

Figure 10: The four wall panel depot/supply locations.

The assembly problems encountered from each of the wall panel depot/supply locations:

A. Requires the use of a tower crane; restrictions due to wind

B. Requires the use of a tower crane; restrictions due to wind; truck has to wait

C. Wall panels must first be transported to the top of the construction; limited depot space available; requires the use of a tower crane

D. Wall panels must first be transported to the floors using a tower crane; assembly requires the use of a tower crane

Each depot/supply location has its own problems in terms of safety and working conditions.

3.3. Using robotic technologies.

It is clear that the final sub-process of the assembly process requires improvement. Figures 11 and 12 show how robotic technologies fit into the assembly process.

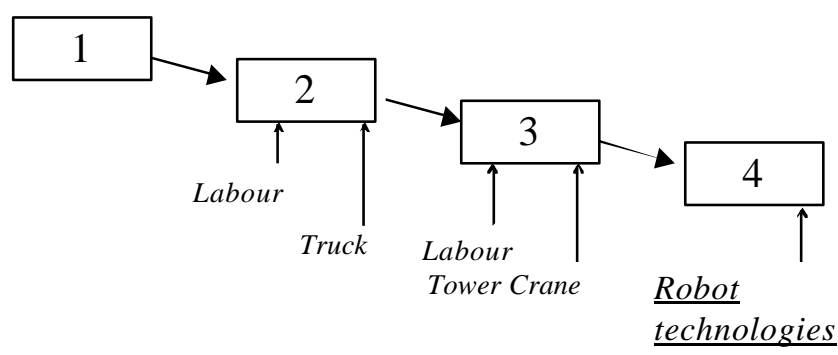

Figure 11: Assembly process involving robotic technologies when supplying wall panels from the depot locations identified in scenarios A, $C$ and $D$ :

1. Wall panels are manufactured at the factory.

2. Wall panels are transported to the construction site by truck.

3. Wall panels are on the construction site.

4. Wall panels supplied from the depots are assembled. 


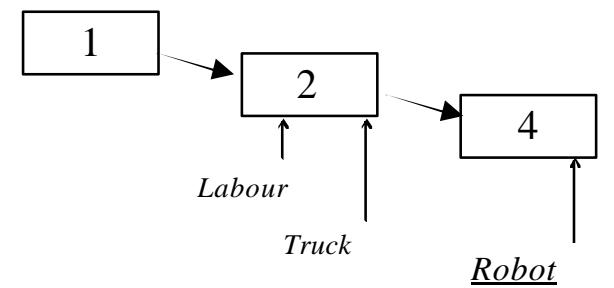

technologies

Figure 12: Assembly process of wall panels supplied from a truck.

1. Wall panels are manufactured at the factory.

2. Wall panels are transported to the construction site by truck.

3. Wall panels supplied from a truck are assembled.

An analysis of the actions that have to be completed indicates that the following functions are required: grabbing the panels, transporting the panels, determining the panel's position and installing. With intelligent equipment and materials, it should be possible to engineer these functions.

\subsection{Integrating functions}

The literature offers several examples demonstrating the integration of various functions of wall curtain systems, particularly in building systems. See Figure 13.

Institut du Monde in Paris.
Latticework screens control the
amount of daylight allowed to
shine through.

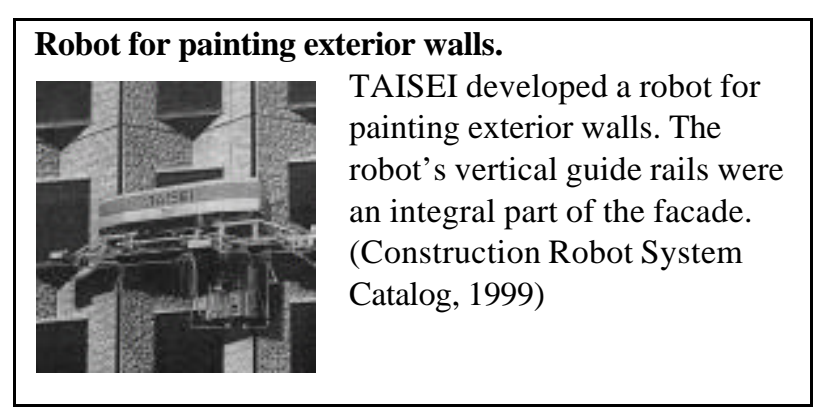

Figure 13: Examples of robot technologies in building systems.

As Figure 13 shows, curtain walls and wall systems are reflecting a growing degree of integration. The solutions are more and more ingenious and are becoming an increasingly integrated part of the curtain wall.

\section{DISCUSSION}

Research has demonstrated that the problems encountered during the installation of wall panels need to be addressed. The application of robotic technologies might offer effective solutions to the problems identified above.

Increasing integration of systems and curtain walls is apparent in the construction industry. This can be attributed to the decreasing scale and growing refinement of the techniques applied. Application is becoming a more integrated aspect, geared to the curtain wall systems.

Previous research and a number of practical examples have demonstrated that robotic technologies offer effective solutions to the problems occurring during the assembly and disassembly of curtain walls. Could the integration of these technologies and the curtain wall systems result in improved, more efficient, cost-saving and sustainable solutions?

When a problem crops up in the construction industry, it is customary to look for and find a solution to that very problem. In the case of implementation problems, for instance, equipment is developed for an existing sub-process. The equipment usually replaces human activities. This approach does not take into consideration the additional potential of the equipment already available or robotic technologies.

Taking a different approach to the problem, armed with a knowledge of the potential of robotic technologies, can facilitate the integration of assembly/disassembly functions and user functions. This gives rise to innovative solutions.

For example, the integration of assembly, disassembly and user functions in terms of the robot-wall panel relationship. This form of integration can be investigated at various levels. See, for instance, Figure 14 for three concepts. 

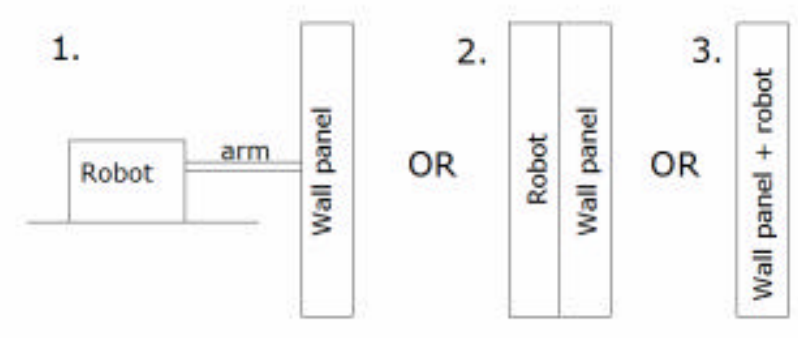

Figure 14: Three concepts for innovative solutions

1. The robot does the work by means of an arm.

2. The robot does the work after attaching itself to the wall panel.

3. The robot and wall panel are integrated into a single element.

These types of approaches offer opportunities for innovative and integrated solutions for wall curtain systems.

\section{CONCLUSIONS}

Examples of the design requirements for a curtain wall system with integrated robotic technologies include:

- Safe construction site for assembly workers.

- Curtain wall is appropriate for high-rise constructions involving a steel load bearing construction.

- The curtain walls are made only of aluminium and glass.

- The curtain wall is equipped for the assembly and disassembly processes. Its components can also be used for user functions (particularly systems) of the facade element.

- Only one remote operator is necessary for the disassembly process.

- $\quad$ Mini and micro-robot devices are used.

The Tokyo Institute of Technology has developed an interesting example of a concept or solution for an automatic assembly system. The Modular Assembly System uses cubic modules to build structures. The modules are outfitted with special automatic handling connections for special assembly robots. See Figure 15.

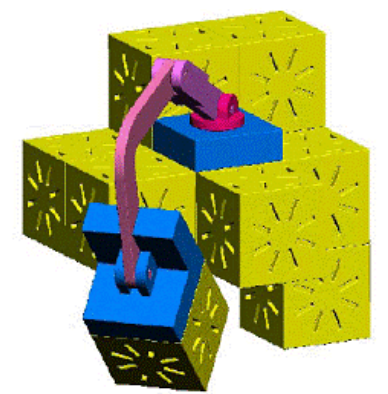

Figure 15: A modular structure and an assembly robot. (Terada, 2005)

\section{REFERENCES}

Arai, T., (2005) Robotics and Automation in Japanese Construction Industries, ISARC 2005 proceedings, Italy.

Bouwen met Staal 133 (1996) Uitdaging voor staal in lichte gevelconstructies (The challenge for steel in light facade constructions), November/ December 1996.

Cobouw (2005) Scan moet veiligheid binnen bedrijven verbeteren (Scan should heighten internal company safety), 18 November 2005.

Construction Robot System Catalog in Japan (1999) JRA Council for Construction Robot Research.

ECTP (2005) Strategic Research Agenda for the European Construction Sector. Achieving a sustainable and competitive construction sector by 2030, www.ectp.org (last viewed 1 May 2006).

Iwanmoto, Masaaki et al, A system of vertically sliding and installing exterior curtain wall of a building, Automation in Construction 3 (1994) 21-34.

IFR, www.ifr.org/picturegallery/servrobappl.htm (last viewed 1 May 2006).

Naticchia, B and A. Carbonari (2005) Integration of an automated active control system in building glazed facades for improving sound transmission loss, ISARC 2005 proceedings, Italy.

Terada Y. and S. Murata (2005) Automatic Assembly System for modular structure, ISARC 2005 proceedings in Italy.

Yu, S.N. et al (2005) The Analysis of the Curtain Wall Installation Robot: Based on the Test in the Construction Site, ISARC 2005 proceedings, Italy.

VOBN (2003) The sky is the limit, Woontoren Westpoint Tilburg. 